https://doi.org/10.48009/2 iis 2007 245-251

\title{
CASE STUDY: PERCEIVED EFFECTIVENESS OF ONLINE LEARNING IN CIS CURRICULA
}

\author{
Gary A. Davis, Robert Morris University, davis@rmu.edu \\ Paul J. Kovacs, Robert Morris University, kovacs@rmu.edu
}

\begin{abstract}
The emergence and rapid growth of the Internet and the media-rich extensions of the World Wide Web have made possible new developments in the way instructors transfer course content to their students. This has resulted in the growth of a new paradigm in pedagogy: technology-enabled learning. Many studies have examined the effectiveness of technology-enabled learning (also called online learning) but very few of the results can be generalized to CIS curricula.
\end{abstract}

The current study examined the perceived effectiveness of online learning courses. Specifically, the study compared the perceived effectiveness of courses offered completely online versus those courses that are offered in a partially-online format.

The results of the study suggest that CIS students rate partially online courses as being significantly more effective than courses offered completely online. In addition, the present study also suggests that CIS students prefer classroom instruction over online delivery methods for conveying CIS course content.

Keywords: On-Line Learning, eLearning, WebBased Learning, CIS curricula

\section{INTRODUCTION}

The emergence and rapid growth of the Internet and the media-rich extensions of the World Wide Web have made possible new developments in the way instructors transfer course content to their students. This has resulted in the growth of a new paradigm in pedagogy: technology-enabled learning. Numerous terms have been used to describe this phenomenon, including Computer-Based Learning, Web-Based Learning, Technology-Supported Learning, eLearning, and Online Learning. For purposes of this research, the term online learning will be used to describe any higher educational course offering that uses technology (i.e., software, electronic mail, and/or the Internet) to deliver all or part of course content.

The proliferation of online learning within higher education has fuelled the ongoing debate as to which delivery method is more effective: online learning or traditional classroom learning [6]. The present research attempts to determine the perceived effectiveness of various delivery methods (including online learning) among undergraduate, graduate, and post- graduate college students.

\section{Background}

Online learning has been cited as having many distinct advantages over traditional classroom learning. Those advantages include 1) reduced time to proficiency, 2) lower logistical costs, 3) added convenience, 4) personalized curricula, and 5) improved measurability of results. Business organizations that utilize online learning often tout a reduction in training expenses, an increase in productivity, and a decrease in employee attrition [7].

Business organizations use online learning in a variety of ways. For example, Siemens uses online learning to deliver a performance simulation course to 10,000 employees world-wide [7]. IBM employs various online learning methods in its world-wide training program involving 300,000 employees [5]. Ford Motor Company frequently uses online learning as an easy way to brief its salespeople and mechanics on the latest automotive products [8]. Few organizations (academic or industry-related), however, have taken the time and effort to assess the perceived effectiveness of online learning, as reported by learning participants.

\section{Partially Online Learning - A Hybrid Approach}

As prevalent as online learning has become in both industry and academia, one prevailing question remains: what is the most effective utilization of online learning (i.e., content delivered completely online or a hybrid model of content that is partially 
delivered online and partially delivered in the classroom)? Industry has typically favored the hybrid approach, opting for a combination of online learning and "on-ground" instruction. Sometimes labeled a "blended approach," the combination of classroom education and online learning has been used by industry to maintain educational quality and foster “. . . greater experiences in interpersonal relationships” [10].

Academia has also taken solace in the hybrid approach to online learning. In their study involving undergraduate management courses, Drennan, Kennedy, and Pisarski found that research subjects “ . . . considered it important to find a balance between the use of emerging technologies and traditional face-to-face lectures" [2]. The results of the above-mentioned study are consistent with the results of a subsequent study involving undergraduate accounting students. In the latter study, the researchers also found that a hybrid or blended approach to online learning was superior to course content delivered entirely online. Specifically, the researchers determined that "The use of technology as an exclusive course delivery method was considered insufficient. Face-to-face tutorials and group learning were central to both student confidence and the learning process” [3].

\section{Research Questions}

Computer and Information Systems (CIS) curricula can present unique challenges to the delivery of course content in an online format that are not found in traditional business and management programs. CIS curricula involve instruction in computer programming languages, requiring extensive drill and practice as well as database courses involving theoretical concepts and hands- on development; both of which can entail an increased interaction with CIS faculty. A recent on-line course shell developed for an Advanced Web Design and E-Commerce course by one of the authors is a case in point. The course required the use of a programming language, design and access of a database, and a theoretical understanding of Web server software and Web design. All of the previously mentioned skills were conveyed without any interaction with a faculty member. It is not yet clear if online learning methods are conducive to the delivery of such course content. Furthermore, it is not clear as to what degree (if any) of online learning is effective in delivering CISspecific course content.

Although research has been conducted with business and management students in higher education to assess the perceived effectiveness of online learning, additional research needs to be conducted with CIS students. The present research examines the perceived effectiveness of online learning, as reported by undergraduate, graduate, and postgraduate CIS students attending a private, mediumsized university to determine if online learning is an effective means of delivery for CIS-related content and to determine which delivery method (i.e., classroom, partially online, or completely online) is perceived to be more effective. The study also sought to determine which delivery method is most appropriate for specific CIS-related course categories. CIS-related course categories examined in the research included: 1) Software Development, 2) Network Administration and Security, 3) Web Development/Web Programming, 4) Multimedia/ Graphics, 5) Office/Productivity Software, 6) Project Management, 7) Systems Analysis and Design, and 8) Business/Competitive Intelligence.

Specifically, the study was conducted to test the following hypothesis:

H1: The perceived effectiveness by CIS students of partially online learning will be higher than the perceived effectiveness of completely online learning.

\section{METHODS AND PROCEDURES}

\section{Approach}

The research involved the administration of a survey instrument to 139 undergraduate, graduate, and postgraduate students enrolled in CIS-related degree programs. The survey was administered online to students in the following undergraduate and graduate courses: Systems Analysis and Design, Project Management, Ethical Issues in Computing (undergraduate), Object-Oriented Systems Analysis and Design, and Competitive / Business Intelligence Systems (graduate). Students completed the online survey on their own time and submitted their anonymous results directly into an electronic database for analysis.

The survey results were analyzed using SPSS statistical software. The Paired-Samples T-Test was used to determine the existence and extent of any difference between the perceived effectiveness of completely online courses and partially online courses. Statistical frequencies were used to 
determine the most effective delivery method for each of the eight CIS-related course categories. Statistical frequencies were also used to describe the demographic breakdown of the research sample.

\section{Sample Characteristics}

A total of 139 undergraduate, graduate, and postgraduate CIS students participated in the study. The participant sampling spanned three undergraduate courses (multiple sections), two graduate courses (multiple sections), and one post-graduate course.
The sample also included students in the Adult and Continuing Education (ACE) undergraduate program, and the Integrated (integrated undergraduate and

graduate degree) Program. As part of the online survey, participants were asked to report their degree program (i.e., undergraduate, graduate, post-graduate, ACE, or Integrated), their sex, their age range, their employment status, and whether or not they had completed an online course in the past. The results from the demographic questions are summarized in Table 1.

Table 1. Demographic Breakdown of Survey Participants

\begin{tabular}{|c|c|c|c|c|c|}
\hline & Undergraduate & $\underline{\text { Graduate }}$ & $\underline{\text { Post-Graduate }}$ & $\underline{\mathrm{ACE}}$ & Integrated \\
\hline \multicolumn{6}{|l|}{ Sex } \\
\hline Male & $70.0 \%$ & $69.8 \%$ & $73.7 \%$ & $33.3 \%$ & $78.6 \%$ \\
\hline Female & 30.0 & 30.2 & 26.3 & 66.7 & 21.4 \\
\hline Modal Age Range & $22-30$ & $22-30$ & $41-50$ & $31-40$ & $22-30$ \\
\hline \multicolumn{6}{|l|}{ Employment } \\
\hline Part-Time Job & $45.0 \%$ & $11.1 \%$ & $0.0 \%$ & $0.0 \%$ & $57.1 \%$ \\
\hline Full-Time Job & 30.0 & 65.1 & 100.0 & 66.7 & 14.3 \\
\hline Not Employed & 25.0 & 23.8 & 0.0 & 33.3 & 28.6 \\
\hline \multicolumn{6}{|l|}{ Online Course } \\
\hline Yes & $62.5 \%$ & $49.2 \%$ & $47.4 \%$ & $66.7 \%$ & $64.3 \%$ \\
\hline No & 37.5 & 50.8 & 52.6 & 33.3 & 35.7 \\
\hline
\end{tabular}

\section{Survey Instrument}

and partially online courses, respectively. Question 4 of the survey instrument asked participants to select the best delivery method for each of the eight CIS

The research participants in the study completed an online survey instrument. The survey instrument was designed to measure the participants' perceptions of effectiveness for various course delivery methods. The instrument was also designed to collect information regarding which CIS course categories are best suited for each delivery method.

The survey instrument consisted of ten closed-ended questions. Two of the questions (survey questions 2 and 3) were designed using a Likert-like scale, with valid responses ranging from "Very Effective" (value =6) to "Very Ineffective" (value $=1$ ). These two questions were designed to solicit participants' perceived effectiveness of completely online courses course categories. Valid responses for each course category included "Classroom Instruction," Completely Online," and "Partially Online." Question 5 of the survey instrument asked participants to report whether the University should "Offer More Courses," "Keep Course Offerings the Same," or "Offer Less Courses" for each of the three delivery methods. The results from Question 5 were not discussed in this research study.

Finally, Questions 6 through $10 \quad$ solicited demographic information from the participants, such as age range, sex, and degree program. In addition, Question 1 of the survey asked the participants if they 
had completed an online course in the past. The online survey instrument is presented in its entirety in the Appendix.

\section{RESULTS}

In order to test the hypothesis in the current study, the resulting means from the survey questions regarding course effectiveness were analyzed. The means were compared using a Paired-Samples T-Test. The survey means, T-Test result, degrees of freedom, and statistical significance are listed in Table 2.

Table 2. Paired-Samples T-Test Results

$\begin{array}{lcccc}\underline{\text { Survey Question }} & \underline{\text { Mean }} & \underline{\text { T-Test }} & \underline{\text { df }} & \underline{\text { Sig. }} \\ \text { Completely Online Effectiveness } & 3.54 & & 138 & .000 \\ \text { Partially Online Effectiveness } & 4.47 & -10.779 & \end{array}$

As displayed in Table 2, the mean perceived effective score was 3.54 for completely online courses and 4.47 for partially online courses. Both scores were based on a one to six scale.

As Table 2 indicates, the perceived effectiveness of partially online courses was higher than the perceived effectiveness of completely online courses. In addition, the difference between the mean scores was statistically significant (at the .01 confidence level).
These results and the .01 confidence level support hypothesis $\mathrm{H} 1$ in the current study.

The survey instrument also asked participants to select the "best" overall delivery method for each grouping of CIS-related topics. The available delivery methods were: Classroom, Completely Online, and Partially Online. The results from these survey questions are summarized in Table 3.

Table 3. Best Delivery Method Comparison Results

\section{Course Category}

Software Development

Network Admin. \& Sec.

Web Dev. / Programming

Multimedia / Graphics

Office / Prod. Software

Project Management

System Analysis \& Design

Bus. / Comp. Intelligence
Classroom

$\underline{\text { Count } \quad \underline{\text { Percent }}}$

93

94

64

73

55

79

83

77
$66.9 \%$

$67.6 \%$

$46.0 \%$

$52.5 \%$

$39.6 \%$

$56.8 \%$

$59.7 \%$

$55.4 \%$
Completely Online

$\underline{\text { Count }}$

2

7

22

19

42

12

18

12

\section{$\underline{\text { Percent }}$}

$1.4 \%$

$5.0 \%$

$15.8 \%$

$13.7 \%$

$30.2 \%$

$8.6 \%$

$12.9 \%$

$8.6 \%$
Partially Online

$\underline{\text { Count }} \underline{\text { Percent }}$

44

$31.7 \%$

38

$27.3 \%$

$38.1 \%$

$33.8 \%$

$30.2 \%$

$34.5 \%$

$27.3 \%$

$36.0 \%$ 
Surprisingly, more research participants selected Classroom as the best course delivery method than the other delivery methods. More specifically, a strong majority of participants selected Classroom delivery as the "best" delivery method for six out of the eight topic groupings.

\section{CONCLUSION AND DISCUSSION}

The hypothesis put forth in this study was supported by the results obtained from the research participants. As expected, research participants rated the perceived effectiveness of partially online courses as higher than that of completely online courses. These findings are consistent with the finding of past studies in which the effectiveness of online course delivery was examined [2, 3].

An unexpected result of the study, however, involved the selection of the "best" delivery method for various CIS-related topics. In all categories of CIS topics, Classroom was selected as the best delivery method by more participants than the other available delivery methods.

Although the results cannot be generalized to all CIS students in all CIS programs, it may be inferred that the CIS students in this study preferred classroom delivery of course content for CIS-related topics. However, if online delivery is to be incorporated into a CIS curriculum, the current study suggests that a hybrid approach (i.e., a combination of classroom and online learning) will be perceived as more effective (than completely online) by the CIS students.

As online learning continues to gain popularity, faculty and advisors must be equipped to help students achieve success. By recognizing variables that contribute to the success of online learners, educators can better prepare students to choose between different learning formats across various subject matter areas.

\section{REFERENCES}

1. Barker, B., \& Brooks, D. (2005). An evaluation of short-term distributed online learning events. International Journal on ELearning, 4(2), 209228.
2. Drennan, J., Kennedy, J., \& Pisarski, A. (2005). Factors affecting student attitudes toward flexible online learning in management education. Journal of Educational Research, 98(6), 331-339.

3. Flynn, A., Concannon, F., \& Bheachain, C. N. (2005). Undergraduate students' perceptions of technology-supported learning: The case of an accounting class. ELearning, 4(4), 427-444.

4. Huang, Z., \& Cappel, J. J. (2005). Assessment of a web-based learning game in an information systems course. The Journal of Computer Information Systems, 45(4), 42-49.

5. Johnson, G. (2004). Conversion anxiety. Training, 41(2), 34-38.

6. Noble, D. F. (Ed.). (2002). Diploma mills: The automation of higher education. New York: Monthly Review Press.

7. Rich, D. (2001). eLearning: A new way to develop employees. Electronic Business, 27(8), 20.

8. Sessa, D. (2001, March 12). Business plan: A look at all the ways companies hope to make money from online education. Wall Street Journal, p. R8.

9. Sitzmann, T. (2005). Is e-learning as effective as classroom learning? $T+D, 59(8), 18$.

10. Trierweiler, C., \& Rivera, R. (2005). Is online education right for corporate learning? $T+D$, 59(9), 44-48. 


\section{APPENDIX}

\section{Survey of I nstructional Methods}

Please complete the following survey concerning the different instructional methods used to deliver courses at $\mathrm{XYZ}$ University.

1) I have taken an online course (either completely online or partially online) in the past?

$\square$ Yes

$\square$ No

2) I perceive the OVERALL effectiveness of courses that are COMPLETELY online as ...

$\square$ Very Effective

$\square$ Effective

$\square$ Somewhat Effective

$\square$ Somewhat Ineffective

$\square$ Ineffective

$\square$ Very Ineffective

3) I perceive the OVERALL effectiveness of courses that are PARTIALLY online as ...

$\square$ Very Effective

$\square$ Effective

$\square$ Somewhat Effective

$\square$ Somewhat Ineffective

$\square$ Ineffective

$\square$ Very Ineffective

4) For each grouping of course topics, select the BEST instructional method

\begin{tabular}{|l|l|l|l|} 
& Classroom Instruction & Completely Online & Partially Online \\
\hline Software Development & $\square$ & $\square$ & $\square$ \\
\hline Network Administration / Security & $\square$ & $\square$ & $\square$ \\
\hline Web Development / Web Programming & $\square$ & $\square$ & $\square$ \\
\hline Multimedia / Graphics & $\square$ & $\square$ & $\square$ \\
\hline Office Software & $\square$ & $\square$ & $\square$ \\
\hline Project Management & $\square$ & $\square$ & $\square$ \\
\hline Systems Analysis \& Design & $\square$ & $\square$ & $\square$ \\
\hline Business / Competitive Intelligence & $\square$ & $\square$ & $\square$ \\
\hline
\end{tabular}


5) For each instructional method listed below, specify whether XYZ should Offer More, Keep Offerings the Same, or Offer Less courses that use the instructional method

\begin{tabular}{|l|l|l|l|} 
& Offer More Courses & Keep Course Offerings the Same & Offer Less Courses \\
\hline Classroom Instruction & $\square$ & $\square$ & $\square$ \\
\hline COMPLETELY Online & $\square$ & $\square$ & $\square$ \\
\hline PARTIALLY Online & $\square$ & $\square$ & $\square$
\end{tabular}

6) I am a(n) ...

$\square$ Undergraduate Student

$\square$ Graduate Student

$\square$ Post-Graduate / Doctoral Student

$\square$ ACE (Adult \& Cont. Ed.) Student

$\square$ Integrated (Undergrad. \& Grad.) Student

7) My current area of study (expected degree) is ...

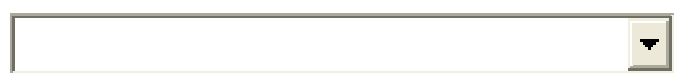

8) I currently have a...

$\square$ Part-Time J ob

$\square$ Full-Time J ob

$\square$ I do not currently have a job

9) My sex is ...

$\square$ Male

$\square$ Female

10) My age range is ...

$\square 18-21$

ㅁ $22-30$

$\square 31-40$

$\square 41-50$

$\square 51$ or older

Thank you for completing the survey. 